\title{
A Critical Assessment of the Golden Hour and the Impact of Procedural Timing in Stroke Thrombectomy
}

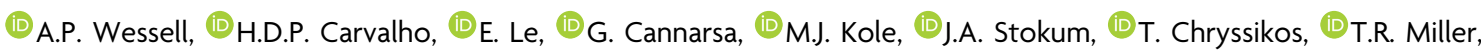

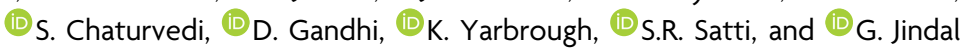

\begin{abstract}
BACKGROUND AND PURPOSE: Previous studies in acute ischemic stroke have demonstrated the importance of minimizing delays to endovascular treatment and keeping thrombectomy procedural timesat $<30-60$ minutes. The purpose of this study was to investigate the impact of thrombectomy procedural times on clinical outcomes.
\end{abstract}

MATERIALS AND METHODS: We retrospectively compared 319 patients having undergone thrombectomy according to procedural time ( $<30$ minutes, 30-60 minutes, and $>60$ minutes) and time from stroke onset to endovascular therapy ( $\leq 6$ or $>6$ hours). Clinical characteristics of patients with postprocedural intracranial hemorrhage were also assessed. Logistic regression was used to determine independent predictors of poor outcome at 90 days ( $m R S \geq 3$ ).

RESULTS: Greater age (OR, 1.03; 95\% Cl, 1.01-1.06; $P=.016)$, higher admission NIHSS score (OR, 1.10; 95\% Cl, 1.04-1.16; $P=.001)$, history of diabetes mellitus (OR, 1.96; $95 \% \mathrm{Cl}, 1.05-3.65 ; P=.034)$, and postprocedural intracranial hemorrhage were independently associated with greater odds of poor outcome. Modified $\mathrm{TICl}$ scale scores of $2 \mathrm{C}(\mathrm{OR}, 0.11 ; 95 \% \mathrm{Cl}, 0.04-0.28 ; P<.001)$ and 3 (OR, 0.15; $95 \% \mathrm{Cl}, 0.06-0.38 ; P<.001)$ were associated with reduced odds of poor outcome. Although not statistically significant on univariate analysis, onset to endovascular therapy of $>6$ hours was independently associated with increased odds of poor outcome (OR, 2.20; $95 \% \mathrm{Cl}, 1.11-4.36 ; P=.024$ ) in the final multivariate model (area under the curve $=0.820$ ). Procedural time was not independently associated with clinical outcome in the final multivariate model $(P>.05)$.

CONCLUSIONS: Thrombectomy procedural times beyond 60 minutes are associated with lower revascularization rates and worse 90day outcomes. Procedural time itself was not an independent predictor of outcome. While stroke thrombectomy procedures should be performed rapidly, our study emphasizes the significance of achieving revascularization despite the requisite procedural time. However, the potential for revascularization must be weighed against the risks associated with multiple thrombectomy attempts.

ABBREVIATIONS: $\mathrm{ICH}=$ intracranial hemorrhage; $\mathrm{mTICI}=$ modified $\mathrm{TICl} ; \mathrm{OTE}=$ onset to endovascular therapy; sICH $=$ symptomatic intracranial hemorrhage

l: chemic stroke is a major source of morbidity and the fifth leading cause of death in the United States. ${ }^{1}$ Mechanical thrombectomy has been well-established as the standard of care for acute ischemic stroke treatment in selected patients presenting with a large-vessel occlusion. ${ }^{2,3}$ Advances in prehospital stroke care and triage, along with technical advances in mechanical thrombectomy,

Received September 20, 2019; accepted after revision March 4, 2020.

From the Division of Interventional Neuroradiology (H.D.P.C., E.L., T.R.M., D.G., G.J.); Departments of Neurosurgery (A.P.W., G.C., M.J.K., J.A.S., T.C.) and Neurology (S.C., K.Y.), University of Maryland Medical Center, Baltimore, Maryland; and Department of Neurointerventional Surgery (S.R.S.), Christiana Care Health System, Newark, Delaware.

Please address correspondence to Aaron P. Wessell, MD, Department of Neurosurgery, University of Maryland Medical Center, 22 S Greene St, S12D, Baltimore, MD; e-mail: apwessell@gmail.com

Indicates article with supplemental on-line table.

http://dx.doi.org/10.3174/ajnr.A6556 have resulted in significant improvement in timing, revascularization rates, and clinical outcomes following stroke thrombectomy. ${ }^{2,4}$

In recent years, there has been investigation into the impact of procedural timing on clinical outcomes. The time from groin puncture to revascularization of $<60$ minutes, termed the "golden hour," has been associated with improved outcomes following stroke thrombectomy. ${ }^{5}$ Additionally, a shorter time from stroke onset to endovascular therapy (OTE) has been linked to more favorable outcomes, including significant early recovery and increased odds of discharge to home. Notably, the association between OTE and improved outcome has been shown to be most significant within the first 2 hours following stroke onset, termed the " 2 golden hours." 6

In the current study, we investigated the significance of thrombectomy procedure duration and the time from stroke onset to endovascular treatment on clinical outcomes after 
mechanical thrombectomy. Additionally, we investigated the impact of revascularization and postprocedural intracranial hemorrhage (ICH), among other variables, on clinical outcomes in patients treated with mechanical thrombectomy.

\section{MATERIALS AND METHODS}

This study was conducted with local institutional review board approval (University of Maryland, Baltimore). We performed a retrospective review of a prospectively maintained data base of all patients undergoing mechanical thrombectomy for the treatment of acute ischemic stroke at a single comprehensive stroke center from April 2012 through February 2019. Patients eligible for inclusion in the study included patients 18 years of age or older who underwent mechanical thrombectomy within 24 hours of stroke onset for treatment of an acute ischemic stroke involving the anterior cerebral circulation.

Data collected included patient demographics, clinical presentation, procedural details, angiographic/radiographic findings, and clinical outcome at 90-day follow-up. Anterior circulation occlusions were defined as occlusions of the ICA, M1 segment of the MCA, or M2 segment of the MCA. Angiographic revascularization grade classified according to the modified TICI score (mTICI) was determined by the neurointerventional surgeon performing the procedure with subsequent verification via independent review of the posttreatment angiogram by an attending neurointerventional surgeon (D.G., T.R. M., G.J., E.L.) and 1 neurointerventional fellow. Differences were adjudicated in a consensus reading when necessary. Successful revascularization was defined as mTICI $2 b, 2 c$, or 3 . $^{7}$

A thrombectomy pass was defined as any stent retrieval thrombectomy attempt or an attempt using aspiration without a stent retriever. Procedural time was grouped according to groin puncture to procedure end time of $<30$ minutes, 30-60 minutes, or $>60$ minutes Procedural time was also dichotomized to less than or greater than 30 minutes for additional analyses. OTE was defined as the time from stroke onset or last known well to groin puncture. Patients were dichotomized according to OTE $\leq 6$ hours or $>6$ hours. Postprocedural ICH was identified on postthrombectomy CT or MR imaging of the brain. Symptomatic intracranial hemorrhage $(\mathrm{sICH})$ was defined as a deterioration in neurologic examination findings attributed to the hemorrhage, as defined by the European Cooperative Acute Stroke Study III definition. ${ }^{8,9}$ The primary outcome of interest was the mRS score at 90 days based on assessment by a neurologist or specialty-trained neurology nurse who did not perform the thrombectomy procedure. An mRS score of $0-2$ was considered a good clinical outcome, and 3-6, a poor clinical outcome.

Procedures were performed using institutional protocols and standard of care. Patient selection for thrombectomy was based on findings from noncontrast CT, CT angiography, and/or MR imaging/MR angiography. Exclusion criteria for the study were the following: 1) mild stroke symptoms, defined as admission NIHSS score of less than four; 2) the presence of a completed large territorial infarction observed on noncontrast CT (ASPECTS <4) or MR imaging (>90-mL infarct volume); 3) functional dependence at baseline, defined as a prestroke mRS less than three; 4) intracranial hemorrhage noted within the targeted stroke territory; or 5) >24 hours from time of known stroke onset. Any discrepancy in the ASPECTS or eligibility for thrombectomy was adjudicated by multidisciplinary consensus between the attending neurointerventional surgeon and attending stroke neurologist. Procedures were performed in a biplane neuroangiography suite (Artis zee; Siemens) by 1 of 4 attending neurointerventional surgeons. Procedures were completed with the patient under moderate/conscious sedation or general anesthesia at the discretion of the attending neurointerventional surgeon.

\section{Statistical Analysis}

The distribution, frequency, and mean values of all clinical and demographic variables were assessed. We compared patients grouped according to procedural time of $<30$ minutes, 30-60 minutes, or $>60$ minutes and OTE of $\leq 6$ hours or $>6$ hours using the $\chi^{2}$ test for categorical variables and the Student $t$ test/ ANOVA for continuous variables. Bivariate analysis was used to compare clinical characteristics among patients who had postprocedural symptomatic hemorrhage and all other patients. Univariate and multivariate logistic regression was used to determine independent predictors of poor outcome at 90 days defined by mRS scores of 3-6.

Logistic regression was performed on all 319 patients. Variables on univariate analysis with a $P$ value $\leq .10$ were included in the final multivariable logistic regression. Select variables with $P$ values $>.10$ on univariate analysis were included in the final logistic regression model due to their clinical relevance. The following variables were included in the final multivariate model: age, NIHSS score, tPA, medical history (hypertension, diabetes mellitus, hyperlipidemia, atrial fibrillation, smoking), OTE of $\leq 6$ hours, procedural time ( $<30$ minutes, 30-60 minutes, $>60$ minutes), mTICI score, moderate sedation versus general anesthesia, number of thrombectomy passes, and postprocedural ICH. The number of thrombectomy passes was grouped according to 1 pass, 2 passes, or $\geq 3$ passes for all analyses. mTICI scores were categorized as $\leq 2 \mathrm{a}, 2 \mathrm{~b}, 2 \mathrm{c}$, or 3 for logistic regression analysis. We assessed potential interactions among all independent variables before inclusion in the final model. A receiver operating characteristic analysis was performed to measure the predictive power of the final regression model. All analyses were conducted using STATA/ SE (Version 16 for Windows; StataCorp). A $P$ value $<.05$ was considered statistically significant for all tests.

\section{RESULTS}

\section{Total Cohort Demographics, Clinical/Procedural Characteristics, and Outcomes}

Three hundred thirty-four eligible patients underwent mechanical thrombectomy for ischemic stroke during the study period. Patients were excluded due to ischemic stroke involving the posterior circulation $(n=12)$, missing clinical information $(n=1)$, and loss to follow-up $(n=2)$, leaving a total of 319 study subjects. The average patient age was $65.10 \pm 0.78$ years. The mean admission NIHSS score was $17.71 \pm 0.31$. Sixty-four percent of patients had an occlusion of the M1 segment, while $22 \%$ and $14 \%$ had occlusions of the ICA and M2 segment, respectively.

AJNR Am J Neuroradiol 41:822-27 May 2020 www.ajnr.org 


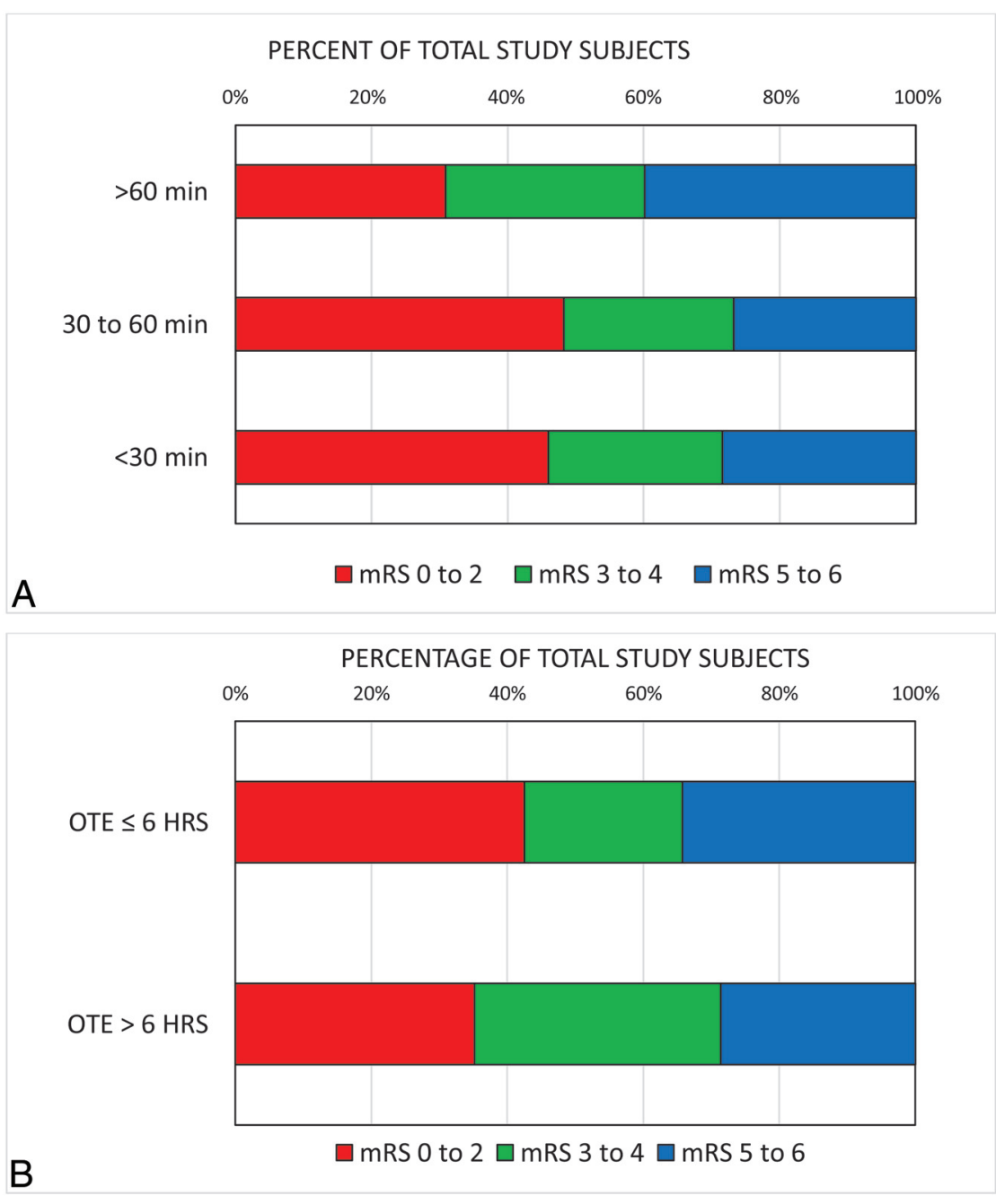

Abbreviations: mRS, modified Rankin Scale; OTE, onset-to-endovascular therapy.

FIGURE. Distribution of 90-day mRS outcome according to procedural time $<30$ minutes, 30 60 minutes, $>60$ minutes $(A)$; and onset to endovascular therapy $\leq 6$ hours or OTE $>6$ hours $(B)$.

respectively) relative to those with a procedural time of $>60$ minutes $(31 \%)$ $(P=.012)($ Fig $1 A)$.

\section{Stroke Onset to Endovascular Therapy}

The mean time from stroke onset or last known well time to endovascular therapy was $244.29 \pm 67.24$ minutes in the OTE $\leq 6$ hours group and $646.93 \pm 312.86$ minutes in the OTE $>6$ hours group $(P<.001)$. The admission NIHSS score was greater for patients in the OTE $\leq 6$ hours group $(18.46 \pm 5.35$ versus $15.85 \pm$ 5.75; $P<.001)$, and there was a trend toward a greater percentage of M1 occlusions relative to ICA or M2 occlusions among patients in the OTE $\leq 6$ hours group $(P=.060)$. Patients with OTE of $\leq 6$ hours were more likely to receive tPA before thrombectomy relative to patients with OTE $>6$ hours $(57 \%$ versus $25 \% ; P<.001)$. The mean time from groin puncture to procedure end was greater among patients in the OTE $\leq 6$ hours group $(61.47 \pm 37.5$ minutes versus $51.74 \pm 30.37$ minutes; $P=$ .029). There was no significant difference in revascularization rates or the number of thrombectomy passes between the $\leq 6$ hours versus $>6$ hours OTE groups. A comparison of patient demographics and clinical characteristics according to OTE $\leq 6$ hours or $>6$ hours is shown in the On-line Table. Forty-three

Revascularization (mTICI 2b, 2c, 3) was achieved in $79 \%$ of cases, and full revascularization (mTICI 2 c or 3 ), in $56 \%$ of cases. Mean groin puncture to procedure end time was 58.7 (2.0) minutes. Forty percent of patients $(n=129)$ from the 319 study subjects achieved a good outcome at 90 days. Patient demographics, clinical characteristics, procedural data, and outcomes are outlined in the On-line Table.

\section{Procedural Time}

A comparison of patients grouped according to procedural time of $<30$ minutes $(n=74), 30-60$ minutes $(n=112)$, and $>60$ minutes $(n=133)$ is outlined in the On-line Table. There was no statistically significant difference in patient age, admission NIHSS score, IV-tPA usage, occlusion site/side, medical history, and time from stroke onset-to-endovascular therapy $(P>.05)$. Shorter procedural times were associated with greater revascularization rates and fewer thrombectomy passes $(P<.001)$ (On-line Table). Patients with procedural times of $<30$ minutes and 30-60 minutes had greater rates of good outcome at 90 days (46\% and $48 \%$, percent of patients in the OTE $\leq 6$ hours group achieved a good outcome at 90 days relative to $35 \%$ in the OTE $>6$ hours group $(P=.225)$ (Fig $1 B)$.

\section{Postprocedural Hemorrhage}

Fifty-seven patients (18\%) had a postprocedural ICH following thrombectomy, 16 of whom (5\%) developed an sICH. There was no difference in admission NIHSS, tPA usage, occlusion site, mTICI score, or OTE among patients with symptomatic hemorrhage compared with all other patients. While not statistically significant, there was a trend toward the presence of $\mathrm{sICH}$ in patients with procedural times of $>30$ minutes versus $<30$ minutes $(P=.099)$. The development of sICH was associated with a greater number of thrombectomy passes $(P=.019)$. All patients who developed $\mathrm{sICH}(n=16)$ experienced poor outcomes at 90 days (Table 1).

\section{Independent Predictors of Poor Outcome}

On univariate analysis, several patient demographic and clinical characteristics were associated with poor clinical outcome at 
Table 1: Clinical and procedural characteristics associated with postthrombectomy symptomatic hemorrhage ${ }^{a}$

\begin{tabular}{|c|c|c|c|}
\hline Variable & $\begin{array}{c}\text { Postprocedural Symptomatic } \\
\text { Hemorrhage }(n=16)\end{array}$ & $\begin{array}{c}\text { Asymptomatic/No } \\
\text { Hemorrhage }(n=303)\end{array}$ & $\begin{array}{c}P \\
\text { Value }\end{array}$ \\
\hline NIHSS & $17.88(6.48)$ & 17.70 (5.55) & .905 \\
\hline tPA & $9(56 \%)$ & 145 (48\%) & .521 \\
\hline \multicolumn{4}{|l|}{ Occlusion site } \\
\hline ICA & $3(19 \%)$ & 67 (22\%) & .927 \\
\hline $\mathrm{Ml}$ & $11(69 \%)$ & $194(64 \%)$ & \\
\hline M2 & $2(13 \%)$ & 42 (14\%) & \\
\hline \multicolumn{4}{|l|}{ mTICI scale } \\
\hline $\mathrm{mTICl} 0$ & $0(0 \%)$ & $25(8 \%)$ & .425 \\
\hline mTICI 1 & $1(6 \%)$ & $11(4 \%)$ & \\
\hline $\mathrm{mTICI} 2 \mathrm{a}$ & $3(19 \%)$ & $25(8 \%)$ & \\
\hline $\mathrm{mTICl} 2 \mathrm{~b}$ & $4(25 \%)$ & $71(23 \%)$ & \\
\hline $\mathrm{mTICI} 2 \mathrm{c}$ & $1(6 \%)$ & $56(18 \%)$ & \\
\hline $\mathrm{mTICl} 3$ & $7(44 \%)$ & 115 (38\%) & \\
\hline OTE (min) & $308.06(87.68)$ & $361.85(258.76)$ & .408 \\
\hline $\begin{array}{l}\text { Groin puncture to } \\
\text { procedure end (min) }\end{array}$ & 64.45 (35.01) & $58.39(35.97)$ & .512 \\
\hline \multicolumn{4}{|l|}{ Procedural sedation } \\
\hline Moderate sedation & 9 (56\%) & $166(55 \%)$ & .909 \\
\hline General anesthesia & $7(44 \%)$ & $137(45 \%)$ & \\
\hline \multicolumn{4}{|l|}{$\begin{array}{l}\text { No. thrombectomy } \\
\text { passes }\end{array}$} \\
\hline 1 Pass & $4(25 \%)$ & $109(36 \%)$ & .019 \\
\hline 2 Passes & $2(12 \%)$ & $104(34 \%)$ & \\
\hline$\geq 3$ Passes & $10(63 \%)$ & $90(30 \%)$ & \\
\hline \multicolumn{4}{|l|}{ Procedure time } \\
\hline$<30 \min$ & $1(6 \%)$ & 73 (24\%) & .099 \\
\hline$\geq 30 \mathrm{~min}$ & $15(94 \%)$ & $230(76 \%)$ & \\
\hline \multicolumn{4}{|l|}{$\mathrm{mRS}$ at 90 days } \\
\hline mRS 0-2 (good) & $0(0 \%)$ & 129 (43\%) & .001 \\
\hline mRS 3-6 (poor) & $16(100 \%)$ & $174(57 \%)$ & \\
\hline Death & $10(63 \%)$ & $59(19 \%)$ & $<.001$ \\
\hline
\end{tabular}

${ }^{a}$ Continuous variables are expressed as mean ( \pm standard error or SD). Categoric binary variables are expressed as No. $(\%) . P<.05$ is considered statistically significant.

90 days (Table 2). On multivariable logistic regression, greater age (OR, 1.03; 95\% CI, 1.01-1.06; $P=.016)$, higher admission NIHSS score (OR, $1.10 ; 95 \% \mathrm{CI}, 1.04-1.16 ; P=.001)$, ICH (OR, 3.48; 95\% CI, 1.55-7.82; $P=.003$ ), and a history of diabetes mellitus (OR, 1.96; 95\% CI, 1.05-3.65; $P=.034$ ) were independently associated with greater odds of poor outcome. Modified TICI scale scores of 2c (OR, 0.11; 95\% CI, 0.04-0.28; $P<.001$ ) and 3 (OR, 0.15; 95\% CI, 0.06-0.38; $P<.001$ ) were associated with reduced odds of poor outcome. Although not significant on univariate analysis, OTE $>6$ hours was independently associated with increased odds of poor outcome (OR, 2.20; 95\% CI, 1.11-4.36; $P=.024$ ) after adjusting for confounding variables included in the final multivariate model (area under the curve $=0.820$ ). Although procedural times of $<30$ minutes and 30-60 minutes had significantly better rates of good outcome at 90 days relative to those with procedural times of $>60$ minutes, procedural time itself and the number of thrombectomy passes did not have an independent association with clinical outcome on the final multivariable logistic regression (Table 2). An additional bivariate analysis comparing patients grouped according to procedural times less than or $\geq 30$ minutes showed no significant difference in outcome (mRS 0-2: 46\% versus 39\%, respectively; $P=.271)$.

\section{DISCUSSION}

The golden hour in stroke thrombectomy, defined by Spiotta et $\mathrm{al}^{5}$ as a procedural time of $\leq 60$ minutes, has been associated with improved outcomes in comparison with longer procedural times. Subsequent recent reports by Alawieh et $\mathrm{al}^{10}$ and Huang et $\mathrm{al}^{11}$ have reinforced the importance of shorter procedural times, noting worse outcomes and greater rates of sICH among patients with extended procedural times, specifically those extending beyond 30 minutes. Similar to these recent reports, ${ }^{10,11}$ greater rates of good functional outcomes among patients who underwent procedures lasting $<30$ minutes or $30-$ 60 minutes relative to procedures of $>60$ minutes $(P=.012)$ were found. Our data also demonstrate a trend toward an increased risk of sICH in those with procedural times of $>30$ minutes. Final TICI scores were significantly different across the procedural time groups. When we accounted for this notable discrepancy in the final multivariate regression analysis, procedural time and the number of thrombectomy passes were no longer independent predictors of outcome. Procedural time, when dichotomized to less than or greater than 30 minutes was, again, not independently associated with outcomes on multivariate analysis. ${ }^{10,11}$ Our results differ in this regard when compared with the reports by Alawieh et $\mathrm{al}^{10}$ and Huang et al. ${ }^{11}$

Our results are similar, however, to recent findings of Tonetti et $\mathrm{al}^{12}$ and Jindal et al. ${ }^{13}$ The data from these studies suggest that the treatment effect still favors recanalization for patients, despite requiring a higher number of thrombectomy passes. Both of these groups concluded that successful recanalization should be pursued despite the number of attempts necessary. Our findings deviate from those reported in the original description of the first pass effect by Zaidat et al. ${ }^{14}$ However, the data from this report did not account for lower rates of revascularization in higher pass cohorts. We continue to believe that it is critical to expedite thrombectomy procedures as much as possible because lengthy procedures delay revascularization and confer some additional risk to the patient with each subsequent thrombectomy pass.

More recently, the 2 golden hours, coined by Peretz et $\mathrm{al}^{6}{ }^{6}$ defined the crucial 2-hour period between the time of stroke onset to endovascular therapy in which patients experience the greatest benefit from mechanical thrombectomy. These results are consistent with those of prior reports that described the importance of early stroke intervention., ${ }^{6,15}$ Our data similarly demonstrate that OTE $>6$ hours is associated with increased odds of poor outcome (OR, 2.20; 95\% CI, 1.11-4.36; $P=.024)$ on 
Table 2: Results of univariate and multivariate logistic regression analysis of clinical parameters and poor outcome (mRS 3-6) at 90 days $^{\mathrm{a}}$

\begin{tabular}{|c|c|c|c|c|c|c|}
\hline \multirow[b]{2}{*}{ Variable } & \multicolumn{3}{|c|}{ Univariate } & \multicolumn{3}{|c|}{ Multivariate } \\
\hline & OR & $95 \% \mathrm{Cl}$ & $P$ Value & OR & $95 \% \mathrm{Cl}$ & $P$ Value \\
\hline Age & 1.03 & $1.01-1.05$ & $<.001$ & 1.03 & $1.01-1.06$ & .016 \\
\hline NIHSS score & 1.10 & $1.05-1.15$ & $<.001$ & 1.10 & $1.04-1.16$ & .001 \\
\hline tPA & 0.66 & $0.42-1.03$ & .067 & 0.75 & $0.42-1.37$ & .354 \\
\hline \multicolumn{7}{|l|}{ Medical history } \\
\hline Hypertension & 1.60 & $0.96-2.68$ & .071 & 1.44 & $0.74-2.80$ & .283 \\
\hline Diabetes mellitus & 1.82 & $1.09-3.04$ & .021 & 1.96 & $1.05-3.65$ & .034 \\
\hline Hyperlipidemia & 1.47 & $0.93-2.31$ & .099 & 1.23 & $0.67-2.26$ & .502 \\
\hline Atrial fibrillation & 1.91 & $1.18-3.10$ & .008 & 1.46 & $0.78-2.76$ & .239 \\
\hline Smoking & 0.64 & $0.41-1.01$ & .051 & 0.75 & $0.42-1.32$ & .319 \\
\hline \multicolumn{7}{|l|}{ Procedural timing } \\
\hline OTE $>6 \mathrm{hr}^{\mathrm{b}}$ & 1.37 & $0.82-2.26$ & .226 & 2.20 & $1.11-4.36$ & .024 \\
\hline Procedure $<30 \mathrm{~min}$ & 0.75 & $0.44-1.26$ & .272 & Ref & & \\
\hline Procedure $30-60 \mathrm{~min}$ & 0.61 & $0.37-0.97$ & .038 & 0.58 & $0.27-1.25$ & .163 \\
\hline Procedure $>60 \mathrm{~min}$ & 2.01 & $1.26-3.21$ & .003 & 1.32 & $0.57-2.08$ & .515 \\
\hline \multicolumn{7}{|l|}{$\mathrm{mTICI}$ scale } \\
\hline $\mathrm{mTICl} \leq 2 \mathrm{a}$ & 4.85 & $2.37-9.93$ & $<.001$ & Ref & & \\
\hline $\mathrm{mTICI} 2 \mathrm{~b}$ & 1.74 & $0.99-3.02$ & .050 & 0.52 & $0.20-1.33$ & .169 \\
\hline $\mathrm{mTICI} 2 \mathrm{c}$ & 0.39 & $0.21-0.69$ & .001 & 0.11 & $0.04-0.28$ & $<.001$ \\
\hline $\mathrm{mTICl} 3$ & 0.50 & $0.31-0.79$ & .003 & 0.15 & $0.06-0.38$ & $<.001$ \\
\hline \multicolumn{7}{|l|}{ Procedural sedation } \\
\hline Moderate sedation & 0.58 & $0.37-0.92$ & .019 & Ref & & \\
\hline General anesthesia & 1.72 & $1.09-2.72$ & .019 & 1.46 & $0.80-2.65$ & .213 \\
\hline \multicolumn{7}{|l|}{ Thrombectomy passes } \\
\hline 1 Pass & 0.53 & $0.33-0.84$ & .007 & Ref & & \\
\hline 2 Passes $^{b}$ & 1.05 & $0.65-1.69$ & .834 & 1.40 & $0.70-2.79$ & .343 \\
\hline$\geq 3$ Passes & 1.93 & $1.16-3.19$ & .011 & 1.62 & $0.72-3.67$ & .244 \\
\hline $\mathrm{ICH}$ & 2.26 & $1.18-4.35$ & .014 & 3.48 & $1.55-7.82$ & .003 \\
\hline
\end{tabular}

Note:-Ref indicates reference.

${ }^{a} P<.05$ considered statistically significant; area under the curve $=0.820$ for final logistic regression model.

${ }^{b}$ Not statistically significant on univariate analysis but included in final model due to clinical relevance.

multivariable logistic regression analysis. An OTE of $>6$ hours was associated with lower rates of tPA usage, lower NIHSS scores, and a trend toward more M2-level occlusions. These factors are known to impact outcomes, and these were accounted for in our multivariate analysis. Patients in the OTE $>6$ hours group also had shorter procedural times than those in the OTE $\leq 6$ hours group (51.74 [30.37] minutes versus 61.47 ([37.58] minutes; $P=.029$ ); this finding may reflect an operator tendency to spend less time on patients in the "late window" and/or might be related to the higher incidence of M2 occlusions seen in the OTE $>6$ hours group. We did not evaluate the impact of the 2 golden hours of OTE on patient outcomes, because only 15 of our patients were treated within 2 hours of onset. Most of our patients with stroke treated with thrombectomy were transferred to our facility from outside hospitals during the study period. ${ }^{6}$

Greater age and NIHSS scores, which are well-established predictors of outcome following stroke, were independent predictors of poor outcome in our final multivariate analysis $(P<.05) .^{2,17}$ Postprocedural ICH was associated with poor outcomes on multivariate analysis, and all patients with $\mathrm{sICH}$ experienced a poor outcome at 90 days. This outcome is similar to that in prior reports. ${ }^{10}$ Also similar to prior reports, a history of diabetes mellitus was found to be predictive of poor outcome (OR, 1.96; 95\% CI, 1.05-3.65; $P=.034){ }^{13,18}$

The present study has limitations. This is a single-center retrospective study, and the triage and thrombectomy techniques we used evolved during the course of the study. A single-center series, however, does ensure some homogeneity with regard to periprocedural and procedural care. Angiographic TICI scoring was initially performed by the operating physician, but subsequent verification of TICI scoring was performed by only 1 attending physician and 1 neurointerventional fellow. Although we created a thorough multivariate model to predict poor outcome with a high degree of predictive accuracy (area under the curve $=0.820$ ), it is possible that we failed to include unmeasured markers of disease severity or other relevant confounding variables. While we attempted to account for differences between the 2 OTE groups in the multivariate analysis, these differences represent a limitation in comparing these groups. Moreover, although we included 319 patients, a larger, higher-powered study is likely needed to help us more precisely understand the role of procedural time itself on outcomes after stroke thrombectomy, because longer procedures and a greater number of thrombectomy attempts confer added risk to the patient.

\section{CONCLUSIONS}

When accounting for lower rates of revascularization in longer procedures, procedural time was not in itself highly predictive of patient outcomes. Thus, our study emphasizes the significance of achieving revascularization despite the requisite procedural time. However, pursuing longer procedures must be weighed against 
the added risk of intracranial hemorrhage associated with multiple thrombectomy attempts.

Disclosures: Gregory Cannarsa-UNRELATED: Employment: University of Maryland Medical Center. Timothy R. Miller-UNRELATED: Grants/Grants Pending: active grants: August, 01, 2013, to present; Co-Inv, Principal Investigator: Gaurav Jindal, (1\%) "ULTRA: Ultra Coils from Start to Finish for the Endovascular Repair of Small Intracranial Aneurysms"; multicenter trial sponsor: Stryker; award amount: \$744,774; assist in patient recruitment, data collection, September 1, 2014, to present; Co-Inv, Site Principal Investigator: Dheeraj Gandhi, (1\%) "BARREL: Prospective, Multi-Center, "Single-Arm Study of the Reverse Medical Barrel ${ }^{\mathrm{TM}}$ Vascular Reconstruction Device (VRD) for Adjunctive Treatment to Embolic Coils for Wide-Neck, Intracranial, Bifurcating/Branching Aneurysms of Middle Cerebral and Basilar Arteries"; multicenter trial, sponsor: Medtronic; award amount: \$26,232; assist in patient recruitment, data collection, September 15, 2015, to present; Co-Inv, Site Principal Investigator: Gaurav Jindal (1\%) "A Prospective, Multi-center, Single Arm Study to Evaluate the Safety and Effectiveness of the CODMAN ENTERPRISE ${ }^{\circledR}$ Vascular Reconstruction Device and Delivery System when Used in Conjunction with Endovascular Coil Embolization in the Treatment of Wide-necked Saccular Intracranial Aneurysms"; multicenter trial, Sponsor: Cerenovus, DePuy Synthes; award amount: $\$ 99,995$; assist in patient recruitment, data collection, January 30, 2018, to present; Co-Inv, Site Principal Investigator: Howard Eisenberg, (1\%) "A Pivotal Clinical Trial of the Management of the MedicallyRefractory Dyskinesia Symptoms or Motor Fluctuation of Advanced Idiopathic Parkinson's Disease With Unilateral Lesioning of the Globus Pallidum Using the ExAblate Neuro System"; multicenter trial, sponsor: InSightec; award amount: $\$ 830,971$; assist in treatment planning and execution, February 21, 2018, to present; Co-Inv, Site Principal Investigator: Gaurav Jindal, (1\%) "Ruptured Aneurysms Treated with Hydrogel Coils-RAGE"; multicenter trial, sponsor: MicroVention; award amount: $\$ 126,350$; assist in patient recruitment, data collection, July 11, 2018, to present; Co-Inv, Site Principal Investigator: Graeme Woodworth, (1\%) "A Study to Evaluate the Safety and Feasibility of Exablate Model 4000 Type-2 to Temporarily Mediate Blood-Brain Barrier Disruption (BBBD) in Patients with Suspected Glioblastoma in the Setting of Planned Surgical Interventions"; single-center trial, sponsor: InSightec; award amount: $\$ 239,027$; assist in treatment planning and execution, August 16, 2018, to present; CoInv, Site Principal Investigator: Dheeraj Gandhi, (1\%) "PHIL DAVF: Study of PHIL Embolic System in the Treatment of Intracranial Dural Arteriovenous Fistulas"; multicenter trial; sponsor: MicroVention; award amount: $\$ 130,000$; assist in patient recruitment, data collection, completed grants, January 13, 2016, to June 1, 2019; Site Principal Investigator, (3\%) "Apollo Onyx Delivery Micro Catheter Post Market Safety Study"; multicenter trial, sponsor: Medtronic; award amount: \$32,500; assist in patient recruitment, data gathering, data analysis, November 2, 2011, to June 2, 2017; Co-Inv, Site Principal Investigator: Gaurav Jindal, $(1 \%)$ "Hydrogel Endovascular Aneurysm Treatment Trial (HEAT)"; multicenter trial, sponsor: Stryker; award amount: $\$ 34,889$; assist in patient recruitment, data collection, November 16, 2013, to November 25, 2014; CoInv, Site Principal Investigator: Elias Melhem, (1\%) "Gadobutrol Enhanced MRA of the Supra-aortic Vessels"; multicenter trial, sponsor: Bayer; award amount: \$79,295; assist in patient recruitment, data collection; November 25, 2013, to December 11, 2017; Site Principal Investigator, (5\%) "Trevo Retriever Registry: Post Market Surveillance Study"; multicenter trial, sponsor: Stryker; award amount: $\$ 337,430$; assist in patient recruitment, data gathering, data analysis, November 10, 2014, to August 20, 2015; Co-Inv, Site Principal Investigator: Dheeraj Gandhi. (1\%) "A Pivotal Study of MicroVention, Inc: Neurovascular Self-expanding Retrievable Stent System LVIS"; multicenter trial; sponsor: MicroVention, award amount: $\$ 45,350$; assist in patient recruitment, data collection, December 8, 2015, to April 3, 2017; Co-Inv, Site Principal Investigator: Gaurav Jindal, (1\%) "Systemic Evaluation of Patients Treated with Neurothrombectomy Devices for Acute Ischemic Stroke (STRATIS) Registry"; multicenter acute stroke registry, sponsor: Medtronic; award amount: \$96,000; assist in patient recruitment, data collection, December 20, 2015, to July 21, 2016; Principal Investigator, (3\%) "Pipeline Flex versus Classic Retrospective Study"; single-center retrospective trial; sponsor: Medtronic; award amount: \$20,000; assist in study design, data gathering, data analysis.* Seemant Chaturvedi—RELATED: Grant: National Institute of Neurological Disorders and Stroke, Comments: Carotid Revascularization and Medical Management for Asymptomatic Carotid Stenosis Trial (CREST-2) Executive Committee*; UNRELATED: Board Membership: New England Journal of Medicine Journal Watch Neurology, Comments: Associate Editor. Dheeraj Gandhi-RELATED: Grant. MicroVention, Comments: National Principal Investigator on a grant (SOFAST)*; UNRELATED: Grants/ Grants Pending. Ultrasound Foundation, National Institutes of Health*; Royalties: Cambridge Press. Sudhakar R. Satti—UNRELATED: Consultancy: Stryker, Cerenovus, Medtronic, Terumo, Penumbra. Gaurav Jindal—RELATED: Grant. Stryker Neurovascular and MicroVention, Comments: research-related grant funding;; UNRELATED: Grants/ Grants Pending. Stryker Neurovascular and MicroVention, Comments: research-related grant funding*; Payment for Lectures Including Service on Speakers Bureaus: Penumbra, Comments: payment for 1 lecture. *Money paid to the institution.

\section{REFERENCES}

1. Lloyd-Jones D, Adams R, Carnethon M, et al; American Heart Association Statistics Committee and Stroke Statistics Subcommittee. Heart disease and stroke statistics-2009 update: a report from the American Heart Association Statistics Committee and Stroke Statistics Subcommittee. Circulation 2009;119:480-86 CrossRef Medline

2. Goyal M, Menon BK, van Zwam WH, et al. Endovascular thrombectomy after large-vessel ischaemic stroke: a meta-analysis of individual patient data from five randomised trials. Lancet 2016;387:172331 CrossRef Medline

3. Hill MD, Goyal M. Treat fast but abandon time from ischemic stroke onset as a criterion for treatment: the DAWN and DEFUSE3 trials. Int J Stroke 2018;13:344-47 CrossRef Medline

4. Audebert HJ, Saver JL, Starkman S, et al. Prehospital stroke care: new prospects for treatment and clinical research. Neurology 2013;81:50108 CrossRef Medline

5. Spiotta AM, Vargas J, Turner R, et al. The golden hour of stroke intervention: effect of thrombectomy procedural time in acute ischemic stroke on outcome. J NeuroIntervent Surg 2014;6:511-16 CrossRef Medline

6. Peretz S, Raphaeli G, Borenstein N, et al. Effect of time from onset to endovascular therapy on outcomes: the National Acute Stroke Israeli (NASIS)-REVASC registry. J Neurointerv Surg 2020;12:13-18 CrossRef Medline

7. Zaidat OO, Yoo AJ, Khatri P, et al; STIR Thrombolysis in Cerebral Infarction (TICI) Task Force. Recommendations on angiographic revascularization grading standards for acute ischemic stroke: a consensus statement. Stroke 2013;44:2650-63 CrossRef Medline

8. Yaghi S, Eisenberger A, Willey JZ. Symptomatic intracerebral hemorrhage in acute ischemic stroke after thrombolysis with intravenous recombinant tissue plasminogen activator: a review of natural history and treatment. JAMA Neurol 2014;71:1181-85 CrossRef Medline

9. Hacke W, Kaste M, Bluhmki E, et al. Thrombolysis with alteplase 3 to 4.5 hours after acute ischemic stroke. N Engl J Med 2008;359:131729 CrossRef Medline

10. Alawieh A, Vargas J, Fargen KM, et al. Impact of procedure time on outcomes of thrombectomy for stroke. J Am Coll Cardiol 2019;73:87990 CrossRef Medline

11. Huang X, Cai Q, Xiao L, et al. Influence of procedure time on outcome and hemorrhagic transformation in stroke patients undergoing thrombectomy. J Neurol 2019;266:2560-70 CrossRef Medline

12. Tonetti DA, Desai SM, Casillo S, et al. Successful reperfusion, rather than number of passes, predicts clinical outcome after mechanical thrombectomy. J Neurointerv Surg 2019 Nov 1. [Epub ahead of print] CrossRef Medline

13. Jindal G, Carvalho HP, Wessell A, et al. Beyond the first pass: revascularization remains critical in stroke thrombectomy. J Neurointerv Surg 2019;11:1095-99 CrossRef Medline

14. Zaidat OO, Castonguay AC, Linfante I, et al. First pass effect: a new measure for stroke thrombectomy devices. Stroke 2018;49:660-66 CrossRef Medline

15. Mulder M, Jansen IG, Goldhoorn RB, et al; MR CLEAN Registry Investigators. Time to endovascular treatment and outcome in acute ischemic stroke: MR CLEAN Registry results. Circulation 2018;138: 232-40 CrossRef Medline

16. Alawieh A, Pierce AK, Vargas J, et al. The golden 35 min of stroke intervention with ADAPT: effect of thrombectomy procedural time in acute ischemic stroke on outcome. J Neurointerv Surg 2018;10:21320 CrossRef Medline

17. Kleine JF, Beller E, Zimmer C, et al. Lenticulostriate infarctions after successful mechanical thrombectomy in middle cerebral artery occlusion. J Neurointerv Surg 2017;9:234-39 CrossRef Medline

18. Jia Q, Zhao X, Wang C, et al. Diabetes and poor outcomes within 6 months after acute ischemic stroke: the China National Stroke Registry. Stroke 2011;42:2758-62 CrossRef Medline 